\title{
Antecedents and Consequences of Consumers' Online Brand-Related Activities (COBRAs) on Social Networking Sites: An Abstract
}

\author{
Rico Piehler, Michael Schade, Barbara Kleine-Kalmer, \\ and Christoph Burmann
}

\begin{abstract}
Brand pages on social networking sites (SNS) enable companies to communicate and interact with their target groups and to build substantial bonds with actual and potential customers. Therefore, brand managers are interested in the motivational antecedents and brand-related consequences of consumers' online brandrelated activities (COBRAs) on SNS brand pages. Based on the level of brand-related activeness, COBRAs can be categorized into consuming behavior (e.g., reading posts and comments, watching videos), contributing behavior (e.g., liking, commenting, and sharing), and creating behavior (e.g., actively producing and publishing content). Unfortunately, previous research mainly focuses on contributing behavior. Therefore, this study investigates motivational antecedents (i.e., social interaction, remuneration, entertainment, and information) and a brand-related consequence (i.e., word of mouth) of COBRAs. Using a sample of 359 German Facebook users, the results of structural equation modeling reveal that consuming behavior positively affects word of mouth, while contributing and creating behaviors have no significant effect. Regarding the motivational antecedents, social interaction positively affects all COBRAs. Remuneration motivations are positively related to contributing and creating behaviors. Entertainment motivations only have a positive effect on consuming behavior. Finally, information motivations do not significantly affect any COBRA type. This article concludes with theoretical and practical implications, limitations, and suggestions for further research.
\end{abstract}

References Available Upon Request

\footnotetext{
R. Piehler $(\varangle) \cdot$ M. Schade $\cdot$ B. Kleine-Kalmer $\cdot$ C. Burmann

University of Bremen, Bremen, Germany

e-mail: rico.piehler@uni-bremen.de; mschade@uni-bremen.de;

limsekr@uni-bremen.de; burmann@uni-bremen.de
} 